\title{
Initial Treatment of Isolated Thoracic Injuries
}

\author{
Alma Alihodzic-Pasalic, Kemal Grbic, Alen Pilav, Adi Hadzismailovic, E. Grbic \\ Clinic of Thoracic Surgery, University Clinical Center in Sarajevo, Bosnia and Herzegovina
}

\begin{abstract}
ntroduction: Isolated thoracic injuries are relatively common and they are on the second place as a cause of death overall trauma. Most patients with isolated thoracic injuries are treated on an outpatient basis while only serious cases are hospitalized. The basis of the treatment of thoracic trauma is efficient cardiopulmonary reanimation followed by an early detection and treatment of life threatening injuries. Less than $15 \%$ of patients with thoracic trauma require thoracotomy. Patients: Only the patients with exclusively isolated thoracic trauma were analyzed. Results: Based on initial diagnostic procedures initial conservative treatment was indicated and sufficient for 63,75\% (204/320) cases while initial surgery treatment was necessary in 36,25\% (116/320) of the injured. In relation to the type of surgery the thoracic drainage was performed in $81,03 \%$ (94/116) while thoracotomy and VATS procedure was necessary for 7,75\% (9/116) of the injured. After the secondary examination or shorter monitoring of the status of the injured, the additional diagnostic procedure was suggested and performed in only $5 \%$ (16/320) of the injured. The average period of the hospitalization for all injured with isolated thoracic trauma was $5,9 \pm 4,0$ days (from 6 hours to 16 days). In cases of patients with blunt injuries the average period of hospitalization was $6,07 \pm 4,26$ days, while for the patients with penetrating trauma it was $5,4 \pm 3,36$ days. The calculated value of t-student test $(0,2766>0,05)$ indicates that there is no statistically significant difference in the period of the hospitalization in relation to the type of trauma (blunt vs. penetrating). The average period of thoracic drainage was 5,58 $\pm 3,3$ days (from 3 to 17 days). The average duration of thoracic drainage in the patients with blunt trauma was $5,81 \pm 2,67$ days, while in the patients with penetrating trauma it was $5,08 \pm 1,99$ days. The calculated value of the probability of $\mathrm{t}-$ test $(0,1478>0,05)$ shows that there is no significant difference in the period of drainage in cases of blunt and penetrating trauma. Out of total number of patients, $98,0 \%$ $(315 / 320)$ of the injured were successfully treated. The complications were found in $1,25 \%(4 / 320)$ cases. Death was the outcome in 1,5\% (5/320) of injured. Conclusion: Based on the results of the initial diagnostic treatment, in majority of injured with isolated thoracic trauma, it was possible to conduct the relevant and appropriate therapeutic procedures. On the basis of relatively short period of thoracic drainage, hospitalization and low rates of morbidity and mortality, it may be confirmed that the application of initial diagnostic and therapeutic protocols of the Clinic for thoracic surgery resulted in the achievement of the successful treatments in majority of the injured for this type of the trauma. Key words: isolated thoracic injuries, initial treatment.
\end{abstract}

Corresponding author: Alma Alihodzic-Pasalic, MD, Msc. Clinic for Thoracic Surgery. Clinical center of University of Sarajevo, Sarajevo, Bolnicka 25. E-mail: alma_ap68@yahoo.com

\section{INTRODUCTION}

Due to improved techniques of first aid and the possibility of more rapid transport of injured an increasing number of patients with severely thoracic injuries reach the hospital alive $(1,2,3)$. Basic principles in the treatment of severe thoracic injuries are: a) conducting a reanimation emergency procedure; b) precise diagnostic procedures, tion procedures are carried out in parallel with diagnostic procedures, and are distinguished depending on the condition and needs of the injured. Today, the principles of treatment of chest trauma were clearly defined and it is necessary to emphasize that the heaviest chest injuries that directly threaten the life of the injured can often be resolved in very simple procedures, one of which is the pleural drainage which in the majority of thoracic injuries is also a definitive treatment. Indication for urgent thoracotomy sets in only $10-15 \%$ of cases. Although less than $15 \%$ of patients with thoracic trauma requires surgery, many unnecessary deaths are the outcome of the inadequate or delayed treatment of injuries that were initially curable (1, $5,6)$. The procedures in the treatment of isolated thoracic injuries that follow after the elimination of conditions that directly threaten the life of the injured, are fighting the pain and respiratory physiotherapy where the toilet of the airways is of particular importance.

\section{AIM}

Analysis of the efficacy of initial therapeutic procedures of injured persons with isolated injuries of the chest on the basis of initial diagnostic procedures. the conditions of urgent stabilization of respiratory and cardiovascular systems. The main aim is the establishment and maintenance of respiratory and cardiovascular function, and can be achieved by freeing airways, providing good ventilation, correction of hypovolemia, low cardiac stroke and minute stroke volume and the anemia $(1,4,5$,). Resuscita-

\section{PATIENTS AND METHODS}

Retrospective analysis included 320 patients hospitalized at the Clinic for Thoracic Surgery of Clinical Center of University of Sarajevo in the period between January 2007 and January 2012 years, with only isolated thoracic injuries. The following data from medical 
history of the Clinic were registered for all the patients: sex, year of birth, date of injury, the cause and mechanism of injury, type of injury, severity of injury, the initial diagnostic procedure, the initial therapeutic procedures, additional diagnostic and therapeutic procedures, indications for emergency thoracotomy, the average duration of pleural drainage, the average length of hospitalization, related complications, morbidity and mortality.

The study was conducted, clinical manipulative and descriptive - analytical processing of patients. Therapeutic procedures that were performed on these patients, depending on the type and severity of injuries were: Conservative treatment: observation and monitoring with chest X-ray control according to the clinical status, thoracocentesis; Surgical treatment: primary surgical wound treatment, thoracostomy and thoracotomy.

The results are presented numerically, graphically and in tables. Statistical analysis was performed by statistical software MS Excel by using the appropriate statistical methods (parametric data were analyzed by calculating the absolute and the percentage value, the arithmetic mean with standard deviations, and Student's t test; nonparametric data are processed in absolute and percentages values and with corresponding chi square test). A defined level of significance was $p<0.05$. Our results were identified and compared with the results of relevant research data presented in contemporary literature.

\section{RESULTS}

Total of 320 patients with isolated chest trauma was hospitalized and treated for at the Clinic for Thoracic Surgery UCC Sarajevo. Male [78.44\% $(251 / 320)]$ to female [21.56\% (69/320)] ratio was 3.64: 1 . The average age of hospitalized patients was $43.17 \pm 17.9$ (2-98 years ). Average age of men was $46.83 \pm$ 17.80 (range 14 to 90 years ), and women $54.91 \pm 18,54$ ( 2 to 98 years) and there is a statistically significant difference $(\mathrm{p}<0.001634)$ in relation to the age by gender. The basic initial diagnosis (history, clinical examination, PA chest radiography, standard laboratory and ultrasonic examination of the thorax and abdomen was performed in 67.81\% (217/320) injured.

Initial treatment (Figure 1) was conservative in $63.75 \%$ (204/320) of cases while surgical treatment was carried out in $36.25 \%(116 / 320)$ injured.

Surgical procedures (Figure 2) were as follows: thoracic drainage in $81.03 \%$ (94/116), PSW (primary surgical wound treatment) $11.20 \%(13 / 116)$ and thoracotomy in $7.75 \%(9 / 116)$ cases.

There was no need for additional treatment (Figure 3) at $88.12 \%(282 / 320)$ injured.

The average period of thoracic drainage was $5.58 \pm 3,3$ days (from 3 to 17 days). The average duration of thoracic drainage in relation to the type of injury (Table 1), penetrating vs. blunt, the average length of thoracic drainage was $5.08 \pm 1.99$ and $5.81 \pm 2.67$ days respectively. Statistically, there is no significant difference in relation to the duration of drainage between penetrating vs. blunt trauma $(0.1478>0.05)$.

The average period of the hospitalization for all injured with isolated thoracic trauma was 5.9 \pm 4.0 days (from 6 hours to 16 days). In relation to the type of injury (Table 2), penetrating vs. blunt, the average length of hospitalization was $5.4 \pm 3.36$ and $6.07 \pm 4.26$ days respectively. Statistically, there is no significant difference in relation to the duration of hospitalization between penetrating vs. blunt trauma $(0.2766>0.05)$.

Figure 4 shows that $98.44 \%(315 / 320)$ of injured was cured and the lethal outcome resulted in $1.56 \%$ (5/320) cases.

Complications were found in 4 patients, $1.25 \%$ (4/320). Three patients developed pleural empyema, and one patient has been creating coagulation haematothorax. In relation to the type of injury all listed patients had blunt chest trauma.

\section{DISCUSSION}

In the initial treatment of injuries with isolated thoracic injuries at the Clinic of Thoracic Surgery, in the fiveyear study, the conservative treatment was more frequently applied and was

\begin{tabular}{|l|l|}
\hline Blunt injuries & $5.81 \pm 2.67$ \\
\hline Penetrating injuries & $5.08 \pm 1.99$
\end{tabular}

Table 1. The average duration of thoracic drainage in relation to the type of injury.

\begin{tabular}{|l|l|}
\hline Blunt injuries & $6.07 \pm 4.26$ \\
\hline With disorders of endopleura & 8.09 \\
\hline $\begin{array}{l}\text { Without disorders of } \\
\text { endopleura }\end{array}$ & 4.49 \\
\hline Penetrating injuries & $5.38 \pm 3.36$ \\
\hline With disorders of endopleura & 6.83 \\
\hline $\begin{array}{l}\text { Without disorders of } \\
\text { endopleura }\end{array}$ & 3.39 \\
\hline
\end{tabular}

Table 2. The length of hospitalization in relation to the type of injury

sufficient in $63.75 \%(204 / 320)$ of the patients. Such treatment consisted of: continuous observation of the condition, pharmacological treatment, physical therapy and thoracentesis.

Initial surgical treatment was necessary in $36.25 \%$ (116/320) injured: thoracic drainage was performed in $81.03 \%$ (94/116), PWS (primary wound surgical treatment) in $11.20 \%(13 / 116)$, thoracotomy and VATS procedure in $7.75 \%$ (9/116) injured. The thoracic drainage was the most frequently indicated thoracic surgery intervention that was performed in $81.03 \%$ (94/116) injured and in $78.72 \%(79 / 94)$ cases was a definitive therapeutic surgical procedure. These data correspond to the data from the available literature in which all the authors state that the pleural drainage is the most common thoracic surgery intervention in thoracic trauma. $(1,2,3,4$ $, 5,6,7)$. Even the most severe forms of the chest injuries that directly threaten the life of the injured can be resolved by 


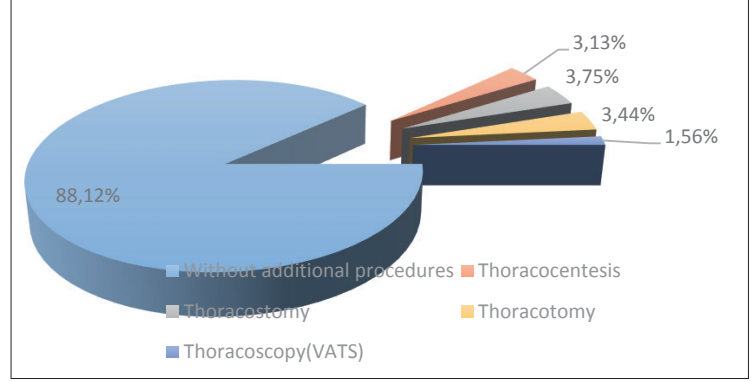

Figure 3. Additional therapeutic procedures

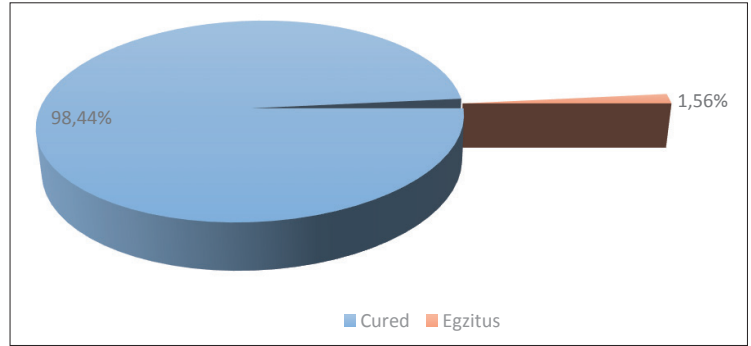

Figure 4. Results of treatment.

simple procedures (the most important pleural drainage), which in the majority of thoracic injuries is an active therapeutic procedure and also the definitive treatment. $(1,2,3,8,9,10,11)$. The primary wound surgical treatment has definitely confirmed (diagnostic value) that, in all of the injured it was the case of not penetrated chest trauma. Out of total number of initially performed thoracotomies, there was one $[11.11 \%$ (1/9) injured] urgent thoracotomy (ER thoracotomy) at the Center for Urgent Medicine. The initial indication was the hemorrhage in drainage system; $>1500 \mathrm{ml}$ with continued bleeding, the absence of vital signs and occurrence of cardiac arrest. In case of one injured [11.11\% (1/9)], the VATS treatment was conducted immediately upon entering the clinic where the initial quantity of evacuated hemorrhagic content was $>1500 \mathrm{ml}$, and the VATS exploration showed the serial ribs fracture while the place of serious bleeding was not found and there was no continued bleeding on the installed drainage system. The remaining emergency thoracotomies [78.88\% (7/9)] after the initial diagnostic work were conducted in the operating room, since it was estimated that the condition of injured allowed the transport to operating room. According to the available literature data, the reports show that the urgent thoracotomy was necessary in 10-15\% injured $(12,13,14,15,16,17)$. As the percentage of the emergency thoracotomies in this study is lower compared to the literature reference, this may be explained by the fact that this work included only injured with isolated thorax injury, while the literature data are mainly related to all injuries of the thorax, either isolated or in poly trauma patients.

After the secondary examination and pursuant to further observation and continuous careful monitoring of the condition of patient, and additional diagnostic tests performed, in $11.88 \%(38 / 320)$ cases and it was necessary to do one of the additional therapeutic procedures as follows: a) thoracostomy of $3.75 \%(12 / 320)$, b) thoracotomy in $3.44 \%(11 / 320)$, c) thoracocentesis at $3.13 \%$ (10/320), and d) VATS in $1.56 \%$ $(5 / 320)$ injuries.

These results indicate that some of the additional therapeutic procedures was required in a relatively low percentage of injuries $(11.88 \%)$ and the procedures were in range from mild, such as pleural puncture, pleural drainage to the standard surgical procedures, such as thoracotomy and VATS procedures. The results obtained in this study indicate the importance of continuous monitoring of injured with isolated thorax injuries because a good knowledge of the pathophysiological mechanisms of thoracic trauma commits to careful monitoring of the injured because of possible progression of previously diagnosed injuries and the risk of various complications that were not present during the initial treatment. Additional types of therapeutic procedures are further adjusted to the findings of diagnostic procedures

Today, the VATS has become a routine diagnostic and therapeutic method to solve the complications of isolated thoracic injuries such as coagulated haematothorax, haematopneumotoraces that cannot be resolved by thoracic drainage and appearance initial pleural empyema. $(7,9,10,11,12)$. The opinions of the majority of the authors, based upon the available literature data, highlights the necessity of the careful and continuous monitoring of injured because of the presence of the realistic possibility of the occurrence of numerous and various complications that require appropriate additional therapeutic treatment $(1,4,7,8,11,14,17,18,19$, $20,21,22)$. The average duration of thoracic drainage in all drained was 5.58 \pm 3.3 days (3-17 days). The duration of thoracic drainage in patients with blunt trauma was $5.81 \pm 2.67$ days, and for patients with penetrating chest trauma it was $5.08 \pm 1.99$ days. Statistically, there is no significant difference in relation to the duration of drainage between penetrating vs. blunt trauma $(0,1478>0,05)$. The average period of the hospitalization for all injured with isolated tho-

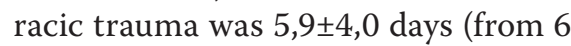
hours to 16 days). In relation to the type of injury, penetrating vs. blunt, the average length of hospitalization was 5.4 \pm 3.36 and $6.07 \pm 4.26$ days respectively. Statistically, there is no significant difference in relation to the duration of hospitalization between penetrating vs. blunt trauma $(0,2766>0,05)$. Based on the obtained results it can be concluded that the average length of hospitalization of the injured with isolated chest trauma is relatively short, although it is a serious injury and the possible complications may directly threaten the life of the injured. Based on the results obtained on the duration of thoracic drainage and hospitalization, it is concluded that for relatively short period of time, pursuant to the well-established indications, the isolated chest injuries can be resolved. This relatively short duration of hospitalization and thoracic drainage is explained by the following facts: a) defined diagnostic - therapeutic protocol for isolated chest trauma, b) competent, qualified, trained and experienced medical staff, c) from the moment of arrival of the injured with isolated thoracic trauma to UCC until his discharged, a complete diagnostic evaluation and treatment is guided by an experienced thoracic surgeon with the trained staff which is of particular importance in the providing of timely, efficient and qualitative overall management of thoracic trauma. Nowadays, the views and opinions about who should treat the injured with thoracic trauma 
are divided. In most centres, the initial diagnostic evaluation and initial treatment is managed by the traumatologist who needed to consult thoracic surgeon $(1,5,16,17,18,19,20)$. It implies that it is a significant advantage to have 24th available thoracic surgeons, who shall at all times properly take responsibility for the complete management of the injured. Based on the effectiveness of the initial treatment, immediate clinical, physical and radiological monitoring of the patient, the average length of hospitalization, and the occurrence of hospital morbidity and mortality of the injured with isolated thoracic trauma, the obtained results show that 98.00\% (315/320) injured were successfully treated. Complications occurred in $1.25 \%(4 / 320)$. The pleural empyema was developed in three patients, and one had been with coagulated haematothorax which was successfully treated. In relation to the type of injury, the blunt thoracic injury was present in all cases. Lethal outcome occurred in $1.5 \%(5 / 320)$ of injured. One patient, mentioned earlier, died during emergency thoracotomy in the ED room. In case of the remaining four patients, the thoracic injury itself was not the direct cause of death since there were additional risk factors. First of all , there was a high age (84, 83 and 80 years). All the injured had significant ancillary comorbidity (chronic patients with advanced cardio-respiratory diseases) where the trauma was only an additional precipitating factor for death. Morbidity and mortality depend on the severity of the injury and the functional condition of the lungs and the age which is often accompanied by a number of chronic illnesses. Morbidity and mortality in this study are low, which indicates that the application of the initial diagnostic-therapeutic protocol of the Clinic of Thoracic Surgery, ensure a successful outcome in the majority of injured with isolated thoracic injuries.

\section{CONCLUSION}

* In 63.75\% (204/320) injured only conservative treatment was initially applied, while the initial surgical treatment was required in $36.25 \%$ (116/320) of injured (thoracic drainage in $81.03 \%$ (94/116) PSW in $11.20 \%$ (13/116), tho- racotomy and VATS procedure in $7.75 \%$ (9/116).

* Pursuant to the calculated, relatively short average duration of thoracic drainage (5.58 \pm 3.3 days) and the average duration of hospitalization (5.9 \pm 4.0 days), low rate of morbidity $[1.25 \%(4 / 320)]$ and low mortality $[1.5 \%$ $(5 / 320)]$, it has been confirmed that the application of the initial diagnostic therapeutic protocol of the Clinic of Thoracic Surgery, resulted in the successful treatment in the majority of these types of injuries.

\section{REFERENCES}

1. Guska S. Torakalna trauma. In: Opšti principi savremene torakohirurške prakse. Medicinski fakultet univerziteta u Sarajevu, Sarajevo, 2012: 629-680.

2. Guska S, Hadžismailović A, Čerimagić Z. Vodič za torakalnu traumu. Ministarstvo zdravstva Kantona Sarajevo. Institut za naučno-istraživački rad i razvoj KCU Sarajevo. Sarajevo, 2007.

3. Schelzig H, Kick J, Orend KH, SunderPlassmann L. Thorax injuries. Chirurg. 2006 Mar; 77(3): 281-296.

4. Miller LA. Chest wall, lung, and pleural space trauma. Radiol Clin North Am. 2006 Mar; 44(2): 213-224.

5. Guska S, Pilav A, Banjanović B, Mušanović S. Primary Surgical Repair of Traumatic Rupture of the Bronchus Iintermedius in Closed Chest Trauma. Scripta Medica. 2008; 39(1, Suppl 1): 227-233.

6. Degiannis E, Bonanno F, Titius W, Smith M, Doll D. Treatment of penetrating injuries of neck, chest and extremities. Chirurg. 2005 Oct; 76(10): 945-958.

7. Alihodžić-Pašalić A, Guska S, Hadžismailović A, Pilav A, Pilav I, Mušanović $S$, Banjanović $B$, Kadić $K$. Ubodna rana grudnog koša $\mathrm{s}$ lezijom aorte. Scripta Medica. 2008; 39(1, Suppl 1): 333-337.

8. Liener UC, Sauerland S, Knoferl MW, Bartl C, Riepl C, Kinzl L, Gebhard F. Emergency surgery for chest injuries in the multiply injured: A systematic review. Unfallchirurg. 2006 Jun; 109(6): 447-452.

9. Guska S. Izolirane povrede grudnog koša kod pacijenata hospitaliziranih na klinici za torakalnu hirurgiju KCU Sarajevo u periodu od 01.01.1999. do 08.10.2000. godine. Medicinski žurnal. 2000: 6(2): 117-125.

10. Cander B, Kalkan E, Girisgin S, Gul M, Coskun F. Emergency operation indications in emergency medicine clinic (model of emergency medicine in Tur- key). Adv Ther. 2006 Mar-Apr; 23(2): 359-363.

11. Plurad D, Demetriades D, Gruzinski G, Preston C, Chan L, Gaspard D, Margulies D, Cryer HG. Pedestrian injuries: the association of alcohol consumption with the type and severity of injuries and outcomes. J Am Coll Surg. 2006 Jun; 202(6): 919-927.

12. Guska S, Pilav I, Mušanović S. Clinical Significance of Isolated Sternal Fracture. Med Arh. 2010; 64(1): 17-21.

13. Sarquis G, Velez SE, Suizer A, Reche F. Diagnostic and therapeutic options for traumatic sternal fractures. Rev Fac Cien Med Univ Nac Cordoba. 2003; 60(1): 13-18.

14. Pilav I, Guska S, Banjanović B, Ćerimagić $\mathrm{Z}$, Mušanović $\mathrm{S}$. Javnozdravstveni značaj povreda grudnog koša u Kantonu Sarajevo. HealthMED 2007; 1(1): 22- 26.

15. Greingor JL, Lazarus S. Chest and abdominal injuries caused by seat belt wearing. South Med J. 2006 May; 99(5): 534-535.

16. Cryer HM. Chest radiography in blunt trauma patients: is it necessary? Ann Emerg Med. 2006 May; 47(5): 422-423.

17. Rodriguez RM, Hendey GW, Marek G, Dery RA, Bjoring A. A pilot study to derive clinical variables for selective chest radiography in blunt trauma patients. Ann Emerg Med. 2006 May; 47(5): 415-418.

18. Mušanović $S$, Guska $S$, Hadžismailović A, Alihodžić-Pašalić A, Pilav I, Pilav A, Banjanović B, Kadić K. Penetrantna povreda toraksa - SMT in situ. Scripta Medica. 2008; 39(1, Suppl 1):37-43.

19. Farooq U, Raza W, Zia N, Hanif M, Khan MM. Classification and management of chest trauma. J Coll Physicians Surg Pak. 2006 Feb; 16(2): 101-103.

20. Shoemaker WC, Bayard DS, Wo CC, Chan LS, Chien LC, Lu K, Jelliffe RW. Outcome prediction in chest injury by a mathematical search and display program. Chest. 2005 Oct; 128(4): 27392748.

21. Vermeulen B, Konstantinidis P. Apparently benign thoracic trauma: what to be aware of? Rev Med Suisse. 2005 Aug 10; 1(29): 1910-1913.

22. Demetriades D, Kimbrell B, Salim A, Velmahos G, Rhee P, Preston C. et al. Trauma deaths in a mature urban trauma system: is "trimodal" distribution a valid concept?. J Am Coll Surg. Sep 2005; 201(3): 343-348.

23. Popper BW, Gifford SM, Usaf MC. et al. Wartime Thoracic Injury: Perspectives in Modern Warfare. Ann Thorac Surg. 2010; 89: 1032-1036. 